\title{
PERHITUNGAN NUMERIK DALAM MENENTUKAN KESTABILAN SOLITON CERAH ONSITE PADA PERSAMAAN SCHRÖDINGER NONLINIER DISKRIT DENGAN PENAMBAHAN POTENSIAL LINIER
}

\author{
AMALINA, MAHDHIVAN SYAFWAN, MUHAFZAN \\ Program Studi Magister Matematika, \\ Fakultas Matematika dan Ilmu Pengetahuan Alam, Universitas Andalas, \\ Kampus UNAND Limau Manis Padang, Indonesia, \\ alin_ku@yahoo.com
}

\begin{abstract}
Abstrak. Penelitian ini membahas tentang kestabilan soliton cerah onsite pada persamaan Schrödinger nonlinier diskrit (SNLD) dengan penambahan potensial linier secara numerik untuk kasus anti-continum limit. Perhitungan numerik dilakukan dengan menyelesaikan masalah nilai eigen yang bersesuaian. Berdasarkan analisis yang dilakukan terhadap nilai eigen tersebut, disimpulkan bahwa soliton cerah onsite selalu berprilaku stabil. Hal ini juga dikonfirmasi oleh evolusi solusi dinamiknya.
\end{abstract}

Kata Kunci: Persamaan SNLD, potensial linier, soliton, anti-continum limit

\section{Pendahuluan}

Persamaan Schrödinger Nonlinier Diskrit (SNLD) merupakan salah satu persamaan yang sering muncul pada berbagai aplikasi ilmu pengetahuan. Beberapa manfaat dari persamaan ini dapat dijumpai pada dinamika sistem osilator tak-harmonik terikat (coupled), perambatan serat optik pada pandu gelombang nonlinier terikat, dan dinamika kondensasi Bose-Einstein [Bose-Einstein condensation (BEC)] yang terperangkap dalam potensial periodik [6].

Persamaan SNLD sangat menarik untuk dikaji karena memiliki solusi spesial yang dikenal dengan soliton. Soliton didefinisikan sebagai gelombang nonlinier terlokalisasi yang selalu mempertahankan bentuknya ketika merambat pada kecepatan konstan sekalipun setelah berinteraksi dengan sesamanya [1,6]. Sifat unik soliton ini sangat berperan penting dalam perkembangan teknologi dan informasi masa depan karena soliton dapat direkayasa sebagai pembawa informasi yang dapat merambat pada media dengan jarak tempuh yang sangat jauh tanpa ada gangguan yang berarti [7].

Persamaan SNLD merupakan salah satu persamaan yang nonintegrable, sehingga salah satu cara yang dapat dilakukan untuk menyelesaikan persamaan tersebut adalah dengan melakukan perhitungan numerik. Dalam aplikasi yang lebih realistik, persamaan SNLD dilengkapi dengan penambahan potensial linier. Sehingga paper ini bertujuan untuk menentukan kestabilan soliton cerah onsite pada persamaan SNLD dengan penambahan potensial linier secara numerik. 
Adapun sistematika penulisan pada paper ini adalah sebagai berikut. Pada bagian kedua dijelaskan persamaan model dan analisis awal. Bagian ketiga membahas tentang konstruksi numerik dalam menentukan solusi dan kestabilan soliton. Kemudian, bagian keempat menjelaskan hasil numerik yang diperoleh dari konstruksi numerik pada bagian sebelumnya. Bagian terakhir berisi kesimpulan.

\section{Persamaan Model dan Analisis Awal}

Persamaan SNLD dengan penambahan potensial linier diberikan oleh

$$
i \dot{\psi}_{n}=-\varepsilon \Delta_{2} \psi_{n}+n \alpha \psi_{n} \pm\left|\psi_{n}\right|^{2} \psi_{n}
$$

dimana $\psi_{n}$ adalah fungsi gelombang terhadap waktu, site $n \in \mathbb{Z}, \dot{\psi}_{n}$ menyatakan turunan $\psi_{n}$ terhadap $t, \varepsilon>0$ merepresentasikan konstanta pengikat (coupling constant) antara dua site yang bersebelahan, $\alpha$ menyatakan konstanta potensial linier, dan $\Delta_{2} \psi_{n}=\psi_{n+1}-2 \psi_{n}+\psi_{n-1}$ adalah Laplacian diskrit pada dimensi satu. Tanda "-" ("+") di depan suku nonlinier pada persamaan (2.1) menunjukkan tipe kenonlinieran focusing (defocusing) yang memuat solusi soliton cerah (gelap).

Persamaan (2.1) memiliki invarian gauge atau invarian phase, yaitu jika dikenakan suatu transformasi $\psi_{n} \rightarrow \psi_{n} e^{i \theta}$ untuk setiap nilai $\theta \in \mathbb{R}$ maka persamaannya tidak berubah. Dengan demikian, pada persamaan (2.1) dapat dilakukan transformasi $\psi_{n}(t)=\phi_{n}(t) e^{i \tilde{\Lambda} t}$, sehingga diperoleh

$$
i \dot{\phi}_{n}=-\varepsilon \Delta \phi_{n}+\Lambda \phi_{n}+n \alpha \phi_{n}-\left|\phi_{n}\right|^{2} \phi_{n} .
$$

dimana $\Delta \phi_{n}=\phi_{n+1}+\phi_{n-1}$ dan $\Lambda=2 \varepsilon+\tilde{\Lambda}$.

Solusi statis dari persamaan (2.2) dapat diperoleh dengan cara mensubstitusikan $\psi_{n}=u_{n}$ ke persamaan (2.2), dimana $u_{n}$ tidak bergantung pada waktu. Sehingga diperoleh persamaan berikut:

$$
-\varepsilon \Delta u_{n}+\Lambda u_{n}+n \alpha u_{n}-\left|u_{n}\right|^{2} u_{n}=0 .
$$

Nilai parameter $\Lambda$ pada persamaan (2.3) dapat dinormalkan menjadi 1 dengan menggunakan transformasi berikut:

$$
u_{n} \rightarrow u_{n} \sqrt{\Lambda}, \varepsilon \rightarrow \varepsilon \Lambda, \alpha \rightarrow \alpha \Lambda .
$$

Secara umum solusi $u_{n}$ merupakan fungsi bernilai kompleks. Meskipun demikian, analisis pada persamaan (2.3) untuk solusi $u_{n}$ dapat disederhanakan tanpa mengurangi keumuman dengan meninjau solusi yang bernilai riil saja [2,4]. Dengan demikian, persamaan (2.3) dapat ditulis menjadi

$$
-\varepsilon \Delta u_{n}+u_{n}+n \alpha u_{n}-u_{n}^{3}=0 .
$$

Paper ini membahas tentang eksistensi dan kestabilan soliton cerah onsite pada persamaan (2.4) dengan syarat batas

$$
u_{n} \rightarrow 0 \text { bilamana } n \rightarrow \pm \infty .
$$




\section{Konstruksi Numerik}

Pada bagian ini dijelaskan konstruksi numerik dari metode Newton-Raphson, penyelesaian masalah nilai eigen, dan metode Runge-Kutta untuk kasus yang sedang dikaji pada paper ini. Semua perhitungan numerik dilakukan pada domain $n \in$ $[-N, N]$ dengan syarat batas

$$
u_{ \pm(N+1)}=u_{\mp N} .
$$

\subsection{Metode Newton-Raphson}

Penyelesaian numerik untuk solusi soliton diskrit stasioner dari persamaan (2.4) dilakukan dengan menggunakan metode Newton-Raphson. Adapun rumus iterasinya diberikan oleh [5]

$$
\mathbf{x}^{(k+1)}=\mathbf{x}^{(k)}-\mathbf{J}^{-1} \mathbf{f}\left(\mathbf{x}^{(k)}\right),
$$

dimana,

$$
\begin{aligned}
& \mathbf{x}=\left(u_{-N} \cdots u_{-1} u_{0} u_{1} \cdots u_{N}\right)^{T}, \\
& \mathbf{J}=\left(\begin{array}{ccccc}
\frac{\partial f_{-N}}{\partial u_{-N}} & \cdots & \frac{\partial f_{-N}}{\partial u_{0}} & \cdots & \frac{\partial f_{-N}}{\partial u_{N}} \\
\vdots & \cdots & \vdots & \cdots & \vdots \\
\frac{\partial f_{N}}{\partial u_{-N}} & \cdots & \frac{\partial f_{N}}{\partial u_{0}} & \cdots & \frac{\partial f_{N}}{\partial u_{N}}
\end{array}\right), \\
& =\left(\begin{array}{ccccc}
1-N \alpha-3 u_{-N}^{2} & -\varepsilon & 0 & \cdots & -\varepsilon \\
-\varepsilon & \ddots & -\varepsilon & 0 & \vdots \\
0 & \ddots & 1-3\left(u_{0}\right)^{2} & \ddots & 0 \\
\vdots & 0 & -\varepsilon & \ddots & -\varepsilon \\
-\varepsilon & \cdots & 0 & -\varepsilon 1+N \alpha-3 u_{N}^{2}
\end{array}\right) \text {, }
\end{aligned}
$$

dan

$$
\mathbf{f}=\left(\begin{array}{c}
-\varepsilon \Delta u_{-N}+u_{-N}+(-N) \alpha u_{-N}-\left(u_{-N}\right)^{3} \\
\vdots \\
-\varepsilon \Delta u_{0}+u_{0}-\left(u_{0}\right)^{3} \\
\vdots \\
-\varepsilon \Delta u_{N}+u_{N}+N \alpha u_{N}-\left(u_{N}\right)^{3}
\end{array}\right)
$$

\subsection{Penyelesaian Masalah Nilai Eigen secara Numerik}

Kestabilan solusi soliton cerah onsite pada persamaan (2.2) dapat ditentukan dengan menyelesaikan masalah nilai eigen dari sistem. Untuk melakukannya, substitusikan $\psi_{n}(t)=u_{n}+\delta \chi_{n}(t)$, dengan $\delta \ll 1$ ke persamaan (2.2) sehingga diperoleh persamaan linier pada $\mathcal{O}(\delta)$ sebagai berikut.

$$
i \dot{\chi}_{n}=-\varepsilon \Delta \chi_{n}+\chi_{n}+n \alpha \chi_{n}-2 u_{n}^{2} \chi_{n}-u_{n}^{2} \bar{\chi}_{n}
$$


Karena $\chi_{n}$ bernilai kompleks, maka solusi dari persamaan (3.1) dapat ditulis dengan $\chi_{n}=\eta_{n} e^{i \omega t}+\bar{\xi}_{n} e^{-i \bar{\omega} t}$. Dengan demikian, diperoleh masalah nilai eigen

$$
\left(\begin{array}{cc}
\varepsilon \Delta-1-n \alpha+2 u_{n}^{2} & u_{n}^{2} \\
-u_{n}^{2} & -\varepsilon \Delta+1+n \alpha-2 u_{n}^{2}
\end{array}\right)\left(\begin{array}{l}
\eta_{n} \\
\xi_{n}
\end{array}\right)=\omega\left(\begin{array}{l}
\eta_{n} \\
\xi_{n}
\end{array}\right) .
$$

Karena unsur-unsur dari matriks koefisien di atas bernilai riil, maka $\bar{\omega}$ juga merupakan nilai eigen. Oleh karena itu dapat disimpulkan bahwa solusi $u_{n}$ stabil jika $\operatorname{Im}(\omega)=0$ untuk setiap nilai eigen $\omega$.

Masalah nilai eigen di atas dapat disederhanakan dengan melakukan eliminasi pada salah satu vektor eigennya. Misalkan yang dieliminasi adalah $\xi_{n}$, sehingga diperoleh

$$
\mathcal{L}_{+}(\varepsilon) \mathcal{L}_{-}(\varepsilon) \eta_{n}=\omega^{2} \eta_{n}=\Omega \eta_{n},
$$

dimana operator $\mathcal{L}_{-}(\varepsilon)$ dan $\mathcal{L}_{+}(\varepsilon)$ didefinisikan sebagai berikut:

$$
\begin{aligned}
& \mathcal{L}_{+}(\varepsilon)=-\varepsilon \Delta-\left(u_{n}^{2}-1-n \alpha\right), \\
& \mathcal{L}_{-}(\varepsilon)=-\varepsilon \Delta-\left(3 u_{n}^{2}-1-n \alpha\right) .
\end{aligned}
$$

Dari hubungan $\Omega=\omega^{2}$ dapat disimpulkan bahwa solusi soliton tidak stabil jika memiliki nilai eigen $\Omega<0$ atau $\operatorname{Im}(\Omega) \neq 0$.

\subsection{Metode Runge Kutta}

Penyelesaian solusi soliton dinamik dari persamaan (2.2) secara numerik diselesaikan dengan metode Runge-Kutta orde 4 dengan rumus iterasi [3] sebagai berikut.

$$
\mathbf{y}^{(k+1)}=\mathbf{y}^{(k)}+h\left[\frac{\mathbf{k}_{1}}{6}+\frac{\mathbf{k}_{2}}{3}+\frac{\mathbf{k}_{3}}{3}+\frac{\mathbf{k}_{4}}{6}\right],
$$

dengan

$$
\begin{aligned}
\mathbf{k}_{1}= & -i\left(-\varepsilon \Delta \vec{\phi}+\vec{\phi}+\operatorname{In} \alpha \cdot \vec{\phi}-|\vec{\phi}|^{2} \vec{\phi}\right), \\
\mathbf{k}_{2}= & -i\left(-\varepsilon \Delta \vec{\phi}+h \frac{\mathbf{k}_{1}}{2}\right)+\left(\vec{\phi}+h \frac{\mathbf{k}_{1}}{2}\right)+\operatorname{In} \alpha \cdot\left(\vec{\phi}+h \frac{\mathbf{k}_{1}}{2}\right) \\
& \left.-\left|\vec{\phi}+h \frac{\mathbf{k}_{1}}{2}\right|^{2}\left(\vec{\phi}+h \frac{\mathbf{k}_{1}}{2}\right)\right), \\
\mathbf{k}_{3}= & -i\left(-\varepsilon \Delta \vec{\phi}\left(\vec{\phi}+\frac{h \mathbf{k}_{2}}{2}\right)+\left(\vec{\phi}+\frac{h \mathbf{k}_{2}}{2}\right)+\operatorname{In} \alpha \cdot\left(\vec{\phi}+\frac{h \mathbf{k}_{2}}{2}\right)\right. \\
& \left.-\left|\vec{\phi}+\frac{h \mathbf{k}_{2}}{2}\right|^{2}\left(\vec{\phi}+\frac{h \mathbf{k}_{2}}{2}\right)\right), \\
\mathbf{k}_{4}= & -i\left(-\varepsilon \Delta \vec{\phi}\left(\vec{\phi}+h \mathbf{k}_{3}\right)+\left(\vec{\phi}+h \mathbf{k}_{3}\right)+\operatorname{In} \alpha \cdot\left(\vec{\phi}+h \mathbf{k}_{3}\right)\right. \\
& \left.-\left|\vec{\phi}+h \mathbf{k}_{3}\right|^{2}\left(\vec{\phi}+h \mathbf{k}_{3}\right)\right),
\end{aligned}
$$

dimana

$$
\begin{aligned}
& \mathbf{n}=\left[\begin{array}{llll}
-N & \cdots & \cdots & \cdots
\end{array}\right]^{T}, \\
& \vec{\phi}=\left[\phi_{-N} \cdots \phi_{0} \cdots \phi_{N}\right]^{T} .
\end{aligned}
$$




\section{Hasil Numerik}

Pada bagian ini dibahas solusi dan kestabilan soliton cerah onsite pada persamaan SNLD dengan penambahan potensial linier secara numerik.

\subsection{Solusi Soliton}

Pada kasus limit anti continum, yaitu untuk $\varepsilon=0$, persamaan (2.4) mempunyai solusi eksak $u_{n}=u_{n}^{(0)}$, dimana setiap $u_{n}^{(0)}$ harus memiliki salah satu dari tiga nilai berikut:

$$
0, \pm 1 \text {. }
$$

Pada dasarnya, terdapat takhingga konfigurasi untuk solusi $u_{n}^{(0)}$. Namun, pada paper ini akan difokuskan untuk solusi soliton cerah onsite yaitu:

$$
u_{n}^{(0)}= \begin{cases}1 & n=0 \\ 0 & n \neq 0\end{cases}
$$

Solusi eksak yang diperoleh dijadikan sebagai tebakan awal dalam menentukan solusi numerik. Adapun solusi soliton untuk beberapa nilai $\varepsilon$ dan $\alpha$ diberikan pada Gambar 1.
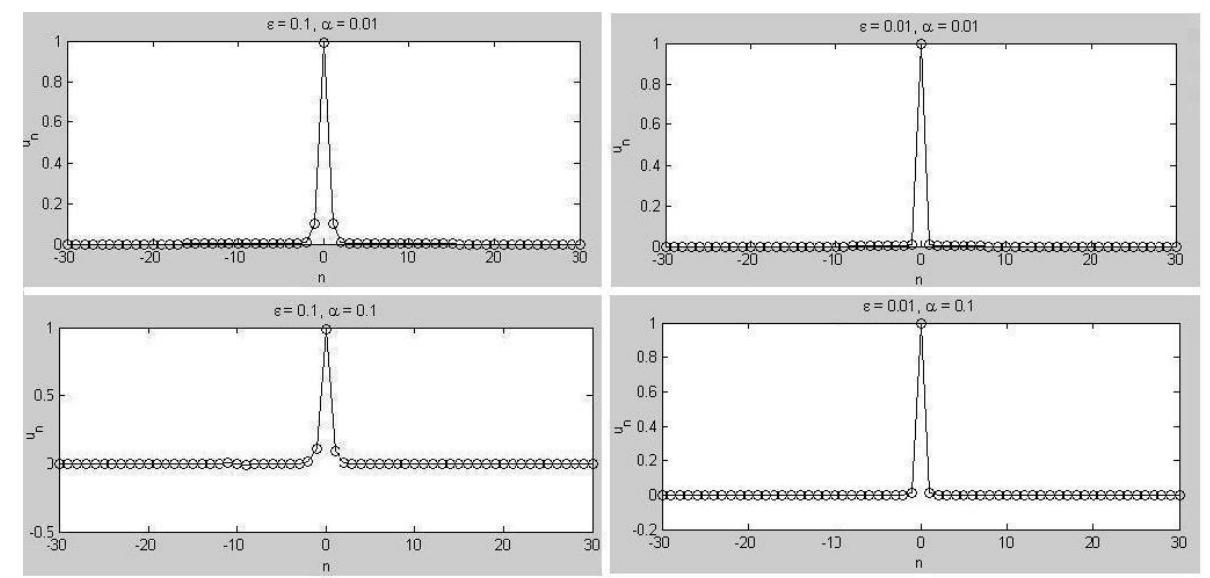

Gambar 1. Solusi soliton cerah onsite untuk beberapa nilai $\varepsilon$ dan $\alpha$

\subsection{Kestabilan Solusi Soliton}

Kestabilan solusi soliton secara numerik diperoleh langsung dengan menyelesaikan masalah nilai eigen. Perhatikan kembali masalah nilai eigen untuk persamaan (2.2). 
Operator $\mathcal{L}_{+}(\varepsilon)$ dan $\mathcal{L}_{-}(\varepsilon)$ dapat ditulis dalam bentuk matriks sebagai berikut:

$$
\begin{gathered}
\mathcal{L}_{+}(\varepsilon)=\left(\begin{array}{ccccc}
1-N \alpha-u_{-N}^{2} & -\varepsilon & 0 & \cdots & 0 \\
-\varepsilon & \ddots & -\varepsilon & 0 & \vdots \\
0 & \ddots & 1-u_{0}^{2} & \ddots & 0 \\
\vdots & 0 & -\varepsilon & \ddots & -\varepsilon \\
0 & \cdots & 0 & -\varepsilon & 1+N \alpha-u_{N}^{2}
\end{array}\right) \\
\mathcal{L}_{-}(\varepsilon)=\left(\begin{array}{ccccc}
1-N \alpha-3 u_{-N}^{2} & -\varepsilon & 0 & \cdots & 0 \\
-\varepsilon & \ddots & -\varepsilon & 0 & \vdots \\
0 & \ddots & 1-3 u_{0}^{2} & \ddots & 0 \\
\vdots & \ddots & -\varepsilon & \ddots & -\varepsilon \\
0 & \cdots & 0 & -\varepsilon 1+N \alpha-3 u_{N}^{2}
\end{array}\right),
\end{gathered}
$$

Adapun vektor eigen ditulis dengan

$$
\vec{\eta}=\left(\eta_{-N} \cdots \eta_{-1} \eta_{0} \eta_{1} \cdots \eta_{N}\right)^{T}
$$

Masalah nilai eigen di atas kemudian diselesaikan secara numerik sehingga diperoleh nilai eigen $\Omega$ dan vektor eigen $\eta_{n}$ untuk setiap solusi $u_{n}$.

Karena kestabilan suatu sistem ditentukan oleh nilai eigen, maka akan dibahas struktur nilai eigen yang diperoleh secara numerik untuk beberapa nilai $\varepsilon$ dan $\alpha$ yang ditunjukkan pada Gambar 2. Pada gambar terlihat bahwa $\operatorname{Im}(\omega)=0$ sehingga dapat disimpulkan bahwa soliton selalu berprilaku stabil untuk nilai-nilai parameter tersebut.

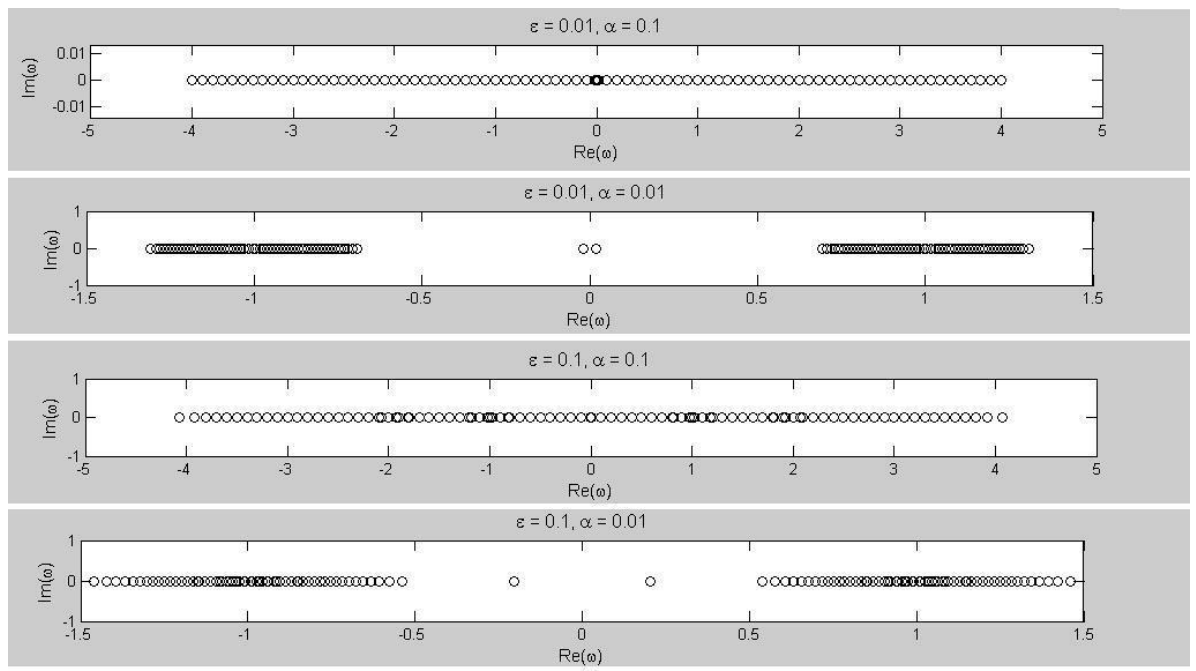

Gambar 2. Struktur nilai eigen dari soliton onsite untuk beberapa nilai $\varepsilon$ dan $\alpha$ 
Perlu diperhatikan bahwa solusi soliton onsite pada sistem persamaan SNLD di bawah pengaruh potensial linier ini terdefinisi dalam rentang nilai $\varepsilon$ dan $\alpha$ tertentu. Kumpulan titik-titik $\varepsilon$ untuk setiap $\alpha$ yang menjadi batas daerah definisi dari soliton ditandai oleh garis putus-putus. Hal ini dapat dilihat pada Gambar 4.2.

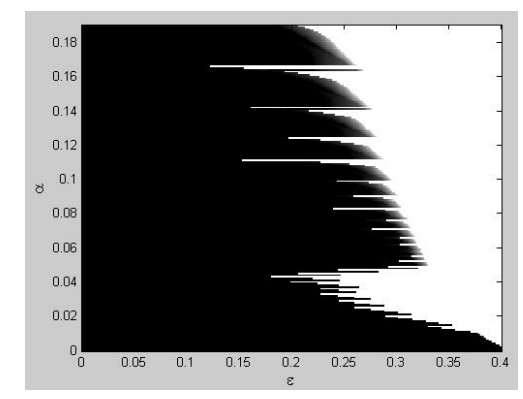

Gambar 3. Daerah kestabilan soliton

\subsection{Solusi Soliton Dinamik}

Selanjutnya ditampilkan evolusi solusi dinamik dari soliton cerah onsite pada persamaan (2.2) yang diselesaikan secara numerik dengan menggunakan metode Runge-Kutta orde 4 yang ditunjukkan oleh Gambar 4. Hal ini bertujuan untuk mengkonfirmasi kestabilan yang telah diperoleh. Pada gambar dapat dilihat bahwa solusi soliton berprilaku stabil, sesuai dengan analisis kestabilan yang dilakukan pada subbagian sebelumnya.
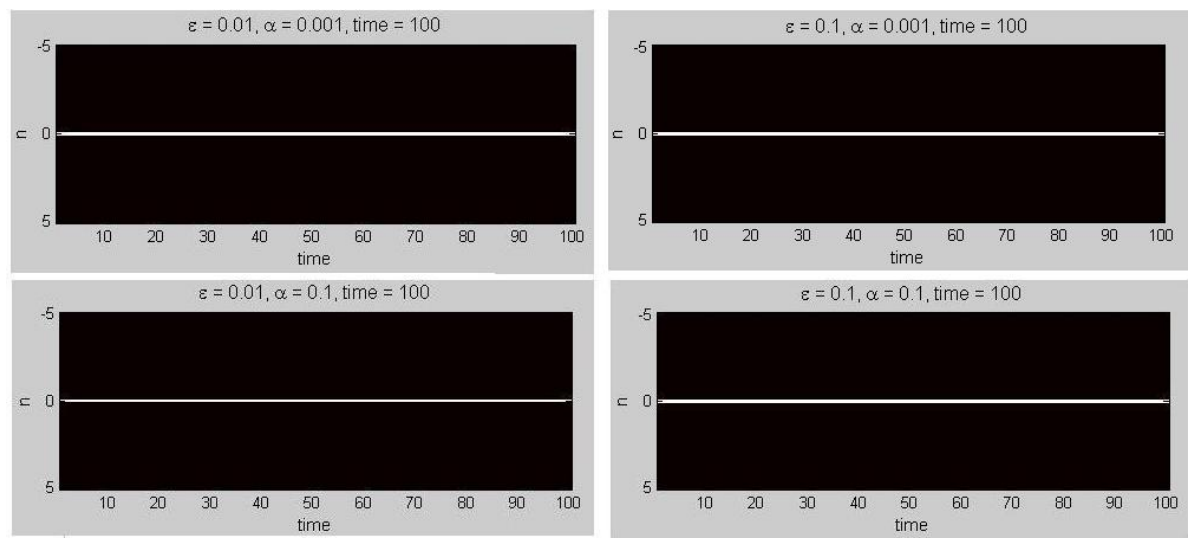

Gambar 4. Solusi dinamik dari soliton cerah onsite pada persamaan (2) untuk beberapa nilai $\varepsilon$ dan $\alpha$ 


\section{Kesimpulan}

Perhitungan nilai eigen secara numerik pada persamaan Schrödinger nonlinier diskrit (SNLD) di bawah pengaruh potensial linier, terutama untuk nilai $\varepsilon$ dan $\alpha$ yang cukup besar memperlihatkan bahwa solusi soliton cerah onsite selalu berprilaku stabil. Hal ini juga sudah dikonfirmasi oleh evolusi dinamik dari solusi soliton itu sendiri.

\section{Ucapan Terima kasih}

Penulis mengucapkan terima kasih kepada Bapak Dr. Admi Nazra, Ibu Dr. Lyra Yulianti, dan Ibu Dr. Yanita yang telah memberikan masukan dan saran sehingga tulisan ini dapat diselesaikan dengan baik.

\section{Daftar Pustaka}

[1] Drazin, P. G., dan Johnson, R. S., 1989, Solitons: An Introduction, Cambridge University Press, Cambridge.

[2] Hennig, D., dan Tsironis, G. 1999, Waves Transmission in Non Linear Lattices, Phys. Rev, 307, 333.

[3] Iserles, A., 2009, A First Course in the Numerical Analysis of Differential Equations, Cambridge University Press, Cambridge.

[4] Kevrekidis, P. G., 2001, Discrete Nonlinear Schrödinger Equation: Mathematical Analysis, Numerical Computations and Physical Perspectives, Phys B, 15, 2833 -2900 .

[5] Mathews, J. H., dan K. D. Fink, 1999. Numerical Methods (Using MATLAB), Prentice Hall, Upper Saddle River.

[6] Scott, A., 2005, Encyclopedia of Nonlinear Science, Routledge, New York and London.

[7] Syafwan, M., 2012, The Existence and Stability of Solitons in Discrete Nonlinear Schrdinger Equations, Disertasi Doktor, University of Notthingham. 